\title{
Corrigendum
}

\section{Emerging threat of H9N2 viruses in poultry of Pakistan and vaccination strategy}

\author{
S. UMAR, S. SARFRAZ, A. MUSHTAQ and M. ATTIQUE
}

doi:10.1017/S0043933916000179. Published online by Cambridge University Press, 27 April 2016.

The authors regret that an error was made in the author affiliations of the published paper (Umar et al., 2016). When originally published the affiliation of 'National Veterinary School of Toulouse, France' was added in error to the author information for S. Umar. The authors would like to apologize for this mistake.

\section{References}

UMAR, S., SARFRAZ, S., MUSHTAQ, A. and ATTIQUE, M. (2016) Emerging threat of H9N2 viruses in poultry of Pakistan and vaccination strategy. World's Poultry Science Journal 72: 343-352. doi:10.1017/ S0043933916000179. 